\title{
Impact of Al and robotics in the tourism sector: a critical insight
}

\author{
Nagaraj Samala, Bharath Shashanka Katkam, Raja Shekhar Bellamkonda and \\ Raul Villamarin Rodriguez
}

\begin{abstract}
Purpose - The purpose of the present article is to highlight the role of Artificial Intelligence (Al) and Robotics in the tourism industry. The various technologies being integrated to improve the service and customer experience in tourism. The expected changes and challenges in tourism in the future are focused in this paper.
\end{abstract}

Design/methodology/approach - A systematic study on the emerging technologies of Al and Robotics applied in the tourism sector is presented in the form of a viewpoint.

Findings - Al certainly enhances tourism experiential services however cannot surpass the human touch which is an essential determinant of experiential tourism. Al acts as an effective complementary dimension to the future of tourism. With the emergence of artificial travel intelligence, it is simpler to make travel arrangements. Al offers travel services that are automated, customized and insightful. Al allows travelers to learn about their behaviors, interests to inclinations and provide a personalized experience. Gone are the days to consult a travel agent, meet him physically and indulge in an endless chain of troubling phone calls to inquire about travel arrangements.

Practical implications - Tourism marketing to see a positive and improved change that will enhance the tourists' overall experience due to the application of Al and Robotics. New emerging technologies like chatbots, virtual reality, language translators, etc. can be effectively applied in Travel, Tourism \& Hospitality industry.

Originality/value - The present viewpoint discusses the application and role of Al and Robotics with the help of relevant industry examples and theory. The present paper highlights the different technologies being used and will be used in the future.

Keywords Chatbots, Robots, Human-Robot interaction, Technologies, Machine learning, Artificial intelligence

Paper type Viewpoint

\section{Introduction}

In the technology-driven times, Artificial Intelligence technology is one of the most innovative inventions that have revolutionized various industries all around the globe. Artificial Intelligence (AI) can be referred to as the development of computer systems that can perform tasks and activities which require human intelligence (Russell and Norvig, 2016, p. 4). Artificial Intelligence first made its appearance during the year 1956 in John McCarthy's Dartmouth Summer Research Project. Over the years, many successes of Al have followed in the form of heuristic searches, character recognition, facial recognition systems, the processing of natural language, and the concept of mobile robotics. By the year 1980s, considerable conceptual progress has been made in the technology-driven field, and its application has increased significantly (Issa et al., 2016). During the 1990s, the technological setting made significant progress, especially in the field of Artificial Intelligence. The growth was mainly because advanced and new kinds of technologies allowed engineers to use large volumes of data, build robots in an efficient manner, and
Nagaraj Samala is based at the Woxsen School of Business, Hyderabad, India and University of Hyderabad, Hyderabad, India. Bharath Shashanka Katkam and Raja Shekhar Bellamkonda are both based at the University of Hyderabad, Hyderabad, India. Raul Villamarin Rodriguez is based at the Woxsen School of Busines, Hyderabad, India.

Received 4 July 2019 Revised 2 November 2019 15 February 2020 Accepted 6 March 2020

(C) Nagaraj Samala, Bharath Shashanka Katkam, Raja Shekhar Bellamkonda and Raul Villamarin Rodriguez. Published in Journal of Tourism Futures. Published by Emerald Publishing Limited. This article is published under the Creative Commons Attribution (CC BY 4.0) license. Anyone may reproduce, distribute, translate and create derivative works of this article (for both commercial and non-commercial purposes), subject to full attribution to the original publication and authors. The full terms of this license may be seen at http://creativecommons.org/licences/by/4.0/ legalcode 
work on improved computing powers. Since then, the Al concept has come a long way and transformed the power of technology. In the $21^{\text {st }}$ century, Artificial Intelligence has reached a climax, and it has the potential to have a profound impact on individuals, organizations, and industries to a significant extent.

In the digitalized era, Artificial Intelligence technology is being used in various industries and not just the Information Technology industry (Nagaraj, 2019, 2020). For example, one can come in contact with $\mathrm{Al}$ in self-driving vehicles, robotic nurses, navigation systems, chatbots, human versus computer games and various other fields (Russell and Norvig, 2016, p. 5).

According to a prediction by McCormick et al., due to the rise in the use of Artificial Intelligence by businesses across different industries, they will be able to steal almost $\$ 1.2$ trillion in a single year from their less-informed rivals by 2020 (McCormick et al., 2016). Some of the major industries where Artificial Intelligence has made its presence are the manufacturing industry, automotive industry, banking, and financial services, healthcare and life sciences, insurance, telecommunications, energy, travel tourism and hospitality and media and entertainment. Rapidly, Al's footprint is expanding in a greater number of industries all across the globe with each passing day (sites.tcs.com, 2019, p. 6). The popularity and application of Al technology are increasing in the industrial setting as it increases the level of innovation and minimizes the processes and activities that are carried out by human factors. In many industries, Al is being used in various functions of organizations such as sales and marketing, customer service, and finance (sites.tcs.com, 2019, p. 6).

In the 21 st century, the tourism industry has seen incredible growth and prosperity at a global level. The international tourist arrivals have increased from 528 million in the year 2005 to 1.19 billion in the year 2015 (www.statista.com, 2019). Today several people are willing to spend money on tourism and traveling. This spending has boosted the demand and overall performance of the industry. Thanks to the growth of the travel and tourism industry, it is regarded to be one of the world's largest sectors that have the power to shape the economic health of a nation. Technology has entered the industrial setting and boosted its performance and quality of service delivery (www.statista.com, 2019). Al has invaded the tourism and hospitality setting, and it is being used to gain a competitive advantage in the dynamic market. The graph presented below shows that various kinds of Al strategies are being used in different industries including the tourism and hospitality industry.

Technology has gradually made way for itself in the tourism industry and reduced the processes that are carried out manually. As the tourism industry has always been an early technology adopter, it has welcomed Al with open arms (World Al Show, 2019). The Artificial Intelligence concept has entered the business context as it can enable marketers in the competitive industrial setting to automate the processes and streamline the business activities. Initially, it was used to simplify the marketing processes, but in the present times, Al technology is leaving a mark on every tourism aspect such as welcoming the guests, serving them and listening to their needs (World Al Show, 2019). Al is being used in the tourism industry for various purposes such as improving the level of personalization, tailoring the recommendations of the customers and guaranteeing fast response times even when the staff members are not present. The presence of artificial intelligence has become so crucial in the industrial setting that it is being used to assist and communicate with the customers and thus strengthen the quality of engagement (revfine.com, 2019).

The objective of this viewpoint is to capture how Artificial Intelligence technology has entered the tourism scene and brought about revolutionary changes in the industrial setting. This viewpoint attempts to give comprehensive knowledge about the various $\mathrm{Al}$ technologies being applied, its implications, challenges and future potential in the Travel, Tourism \& Hospitality segment. In the technology-driven times, the topic can shed light on 
the power of Artificial Intelligence and the implications that it has on the industrial environment. How Al has redesigned, the traveling and tourism process has been critically presented here. A holistic assessment has been carried out to comprehend how Artificial Intelligence is converting the regular tourism industry into a smart industrial hub.

\section{Scope of $\mathrm{Al}$ in tourism as an industry}

Although the Artificial Intelligence (AI) is a contemporary issue, there are few interesting findings that trigger the usage of Al in the Travel, Tourism \& Hospitality Industry. There were few studies conducted in the recent past, on the usage of Al in Travel, Tourism \& Hospitality Industry by companies like Tata Consultancy Services, Google Travel, Trip Advisor, etc. (Viglia et al., 2014). These studies revealed some of the important findings that are advantageous to the Travel \& Tourism companies. A survey done by Tata Consultancy Services (TCS) founded that 85 per cent of the travel \& hospitality service providers use Artificial Intelligence in their business (Anurag, 2018). Studies report that this may be because of the rapid rise in digital travel sales, which are expected to cross $\$ 800$ billion by the year 2020 (Chawla, 2019). Google Travel \& Trip Advisor founded that 74 per cent of the customers plan their tourism trips using the Internet, in which more than 45 per cent of customers plan using smartphones (Peranzo, 2019). Other surveys indicate that 85 per cent of customers decide their travel activities, after reaching their destination (thinkwithgoogle. com, 2016). 36 per cent of customers prefer the Interactive booking process \& 80 per cent of them choose self-service technologies over traditional services (Peranzo, 2019). 90 per cent of the customers expect relevant information about the trip while they travel to the destination spot (thinkwithgoogle.com, 2016).

Taken together, these results would seem to suggest the customers' tendency towards internet \& self-service technologies. These findings would tempt the marketers to incorporate Artificial Intelligence in the form of interactive \& self-service technologies to deliver enhanced customer experience. The finding of these surveys not only suggests the customers' tendency towards the technology but also infer the aspect of "Timeliness". The customers are so particular about the timeliness of the services, which they receive (Kim et al., 2014). Majority of the customers are not ready to accept the services before the travel, rather they expect these services at the time of their travel. Findings also reveal that the majority of the customers prefer self-service technologies over traditional services. These self-service technologies are largely possible, by the usage of Artificial Intelligence (Ivanov and Webster, 2017; Ivanov et al., 2017).

Besides, these factors, there are several other factors that influence the travel, tourism \& hospitality industry. Important factors that influence the selection of the Tourism, Travel \& Hospitality services include Natural Resources, General Infrastructure facilities, Tourist Infrastructure, Destination tourism infrastructure (Beerli and Martin, 2004). Natural Resources include scenic beauty, lakes, mountains, deserts, variety \& uniqueness of flora \& fauna, weather conditions (temperature of the region, rainfall, humidity, etc.). General Infrastructure facilities include road, public \& private transport. Tourist Infrastructure includes hotel \& accommodation facilities, restaurants, bars, discotheques, clubs, theme parks, entertainment \& sports activities, water parks, zoos, casinos, trekking, adventure activities, shopping malls, etc. Destination tourism infrastructure includes human resources, safety measures at that place (Beerli and Martin, 2004; Kaushik et al., 2010; Seyidov and Adomaitienè, 2016).

Artificial Intelligence can provide a wide range of information on all the key factors such as Natural Resources, General Infrastructure facilities, Tourist infrastructure facilities, Destination tourism infrastructure facilities, etc. Al technology can surpass human performance by offering a wide range of information on all the key factors within no time. Given these circumstances, the Artificial Intelligence may outperform human services. Artificial Intelligence easily addresses the requirements of the customers by providing 
timely information to customers on the key factors such as Natural Resources, General Infrastructure facilities, Tourist infrastructure facilities, Destination tourism infrastructure facilities, etc. This information can be in the form of interactive messages, self-service technologies, chatbots, audio tours, virtual tours, interactive booking process, facial recognition technologies, language translations, cross-selling \& up-selling, competitive pricing, easy shopping, etc., which are discussed in the later sections in detail.

\section{Artificial intelligence in tourism}

There are several new technologies that evolved in the domain of Artificial Intelligence. These technologies were helpful in delivering a novel experience to the customers. These technologies include Facial Recognition technologies, Virtual Reality applications, Chatbots, Robots, Artificial Intelligence in Google Maps, Language Translators, Audio tours, Ease of Shopping, etc.

\subsection{Facial recognition}

Facial Recognition is an application of Al technology which is gaining greater importance and application across various industries for varied purposes. Facial Recognition is being adapted in the travel and tourism industry also at a large scale. For example, travelers have to undergo a repeated set of complex processes in the form of scrutinization of travel documents by various authorities like customs, immigration \& airports. This complexity in the process consumes a lot of precious time, which further leads to a kind of frustration in the tourists (Patel, 2018). To mitigate these kinds of disturbances, Facial Recognition technologies have come into play. This technology recognizes the face of the tourists, verifies it with the face in the documents \& provides hassle-free check-ins. By using this technology, tourists can comfortably pass through the airport check-ins \& all other station check-ins, without the document verifications by various authorities such as immigration, customs, etc. (Chang and Yang, 2008). This technology is currently implemented by the ShoCard Organization for the airlines (Saulat, 2018).

\subsection{Virtual reality}

Virtual Reality (VR) technology generally uses the VR headset to create a simulated environment. This simulated environment gives an experience of virtual reality. The customer using the VR technology experiences the environment to a great extent in a 3D, digital world (Guttentag, 2010). In recent days, this technology is used by the travel, tourism \& hospitality companies. These companies demonstrate tourist spots \& hotel locations by using 3D videos. There is a major gap existing between customers \& hoteliers. The customers at a far distance are typically unaware of the ambiance of the hotel, the quality of the rooms, etc. Hoteliers describe their hotel on the website; provide few images \& videos that would not give a complete picture to the customers. Majority of the time, this kind of approach results in ambiguity to the customers. The customers, who are at a far distance, are unable to assess the ambiance \& environment of the hotel, Quality of the hotel rooms, facilities in the hotel, etc. This problem is easily addressed by Virtual reality applications (Guttentag, 2010; Yung and Khoo-Lattimore, 2019).

There are various Virtual reality applications used in the Tourism \& Hotel Industry. Few of them are Virtual hotel tours, Virtual travel experiences, Virtual Booking Interface. Virtual hotel tours include the demonstration of the hotel environment, its facilities in the form of 3Dvideos. This makes the customers encounter a real-time experience about the facilities in the hotel (Barnes, 2016). The customers would like to experience the travel \& exploration of the tourist spots before they move to the tourist spots. This is done by searching relevant information on the Internet in the form of customer reviews etc. (Kim and Hardin, 2010). With the advent of Virtual reality technologies, there was a radical change in the availability of 
information to customers. This information makes the customers decide about their travel beforehand.

Virtual reality technologies are perfect gateways to travel \& explore the unseen locations beforehand. Marketers provide the virtual journey to the customers into the hotels \& tourism spots by partnering themselves with the hotels, tourism spots (i.e. museums, zoo parks \& all other recreational spots) (Jung et al., 2016; Jung et al., 2017). In the recent past, there are few hotels namely Marriott hotels, Atlantis Dubai Hotels who partner themselves with the marketers to provide the customers a virtual experience (Van Kerrebroeck et al., 2017). Virtual Booking Interface allows the customers real-time, simulated experience of walking through a plane \& selecting the seat in the aircraft. Customers also select other services like cab service \& make the payment. This easy demonstration of booking the flight tickets \& other services in the form of 3D-videos allow the customers to book by themselves, without approaching any consultancies. This helps the airlines to become the next generation retailers. Few companies such as Navitaire airlines use the services of virtual booking interface (Wilde, 2017).

\subsection{Chatbots}

"Chatbot is a piece of software that conducts a conversation via auditory or textual methods." There are mainly two types of Chatbots, namely Text message-based chatbots \& Voice based chatbots. Text message-based chatbots provide message services to the queries of customers in the form of text messages. Voice-based chatbots provide message services to the queries of the customers in the form of voice-based messages (Kumar et al., 2018; Kumar et al., 2016). Chatbots are typically computer software machines, which are pre-programmed to answer the simple questions raised by the customers (Oh et al., 2017). Chatbots has inbuilt programs that identify the keywords within the questions that trigger the number of responses in response to a single question. This key feature of sending out multiple responses to a single question immediately has been a notable aspect of chatbots (Makar and Tindall, 2014). Moreover, chatbots can be accessed 24/7 for all the 365 days in a year. These key features made chatbots to replace the employees. Some companies offer a unique experience using travel chatbots. The travelers can ride the car on their own without any guide \& the travel chatbot installed in the car keeps on describing each place. This technology is named as an Audio tour, which is preferred by the travelers who wish to have privacy \& travel alone with their families (Boiano et al., 2019).

Every hotel wants to have your guests a great experience. Inevitably, the guests need some or the other information about the hotel facilities. That's where the Chatbots come into play. Personalization is a key component that marketers need to integrate with their services. Especially, Voice-based chatbots provide a high-profile personalized service to its customers. It serves the customers by offering a wide range of services like ordering food services, cab services, reading out the messages, scheduling the tasks \& appointments, setting up alarms, room services, house-keeping services, informing the hotel facilities, etc. (Gajdošík and Marciš, 2019). All in all, it acts as an assistant to the guest. Chatbots can even store the previous data of the guests by which they can suggest recommendations based on past purchases \& activities. These voice-based chatbots are specially meant to improve hospitality, which further improves customer engagement \& experience (Nagaraj and Singh, 2018, 2019). Delivering a great guest experience can be possible with chatbots for hospitality. Few hotels use the chatbots namely, Marriott hotels, Hyatt hotels, GRT hotels (Gajdošík and Marciš, 2019; Seal, 2019).

\subsection{Robots}

Robots are another type of Al technology that is strengthening their presence in the tourism industry. These technology-driven assistants are using the Internet of Things (IOT) 
technology to do simple activities such as turning on the bedroom lights, turning off the television, handling systems to ensure the luggage is checked in automatically and receiving the guests in a hotel. Robot receptionists have become a trending thing in the tourism industry, which has a direct implication on the interaction and experience of the customers and guests. They are even taking care of the room service aspects so that the guests will not face any kind of issue while checking in to a new hotel room. In some of the reputed hotels of Marriott such as St. Regis, Westin and Aloft, the Alexa robot has been getting a lot of attention. Similarly, in airports, robots have started making their presence, and they are being used as guides and assistants. Some of the main advantages of robots in the tourism industry include enhanced customer experience, simplification of the work process, the ability of human factors to focus on other activities and improved efficiency of the tourism business.

The introduction of $\mathrm{Al}$ in the tourism industry is a reality of the current era. For instance, a reputed Japanese tourism and hospitality company Henn-a Hotel has introduced various kinds of robots in its workforce, including dinosaur robots. These robots are responsible for taking care of the front desk activities and receiving guests. Even though it might sound pretty weird, this is one of the examples that show the Al technology has come a long way in the tourism industry, and it has a long way to go as well. Thus, Al has introduced a silent revolution in the hospitality and tourism industry that cannot be ignored.

\subsection{Google maps}

Google Maps using GPS technology assisted the travelers by keeping them informed about the directions. Usage of Artificial Intelligence technology in Google Maps advanced the information by keeping the travelers informed about the accidents \& traffic jams. Although Google Maps eases the travel journey by locating the right directions; travelers repeatedly encounter a common problem. The customers end up their travel by completely traveling in the wrong direction, which is realized after traveling a fair bit of distance (Marouane et al., 2014). This experience brings a lot of confusion \& irritation to travelers. To overcome this hurdle, Google Maps came up with a new solution of incorporating the Visual Positioning System (VPS) to ease the travel journey. This newer version makes use of the Visual Positioning System (VPS), which differs itself, from the Global Positioning System (GPS). Visual Positioning System uses Artificial Intelligence technology that gives the live view of the real world \& visual landmarks in front of travelers (Anup et al., 2017).

Google Maps with the help of Artificial Intelligence are now able to provide a live view of the real world. The new feature in Google Maps immediately starts the camera \& starts scanning around, to find the visual landmarks like buildings, storefronts, etc. Travelers can switch on the Google Maps application to figure out their exact location \& experience the live view of Google Maps. It would provide details about the shops, companies, hotels, malls, cinema theatres, restaurants, canteens, recreational zones, etc., thereby providing Location-based experiences (Xiao et al., 2018). By making use of the live view, the travelers travel in a proper direction, without any confusion (Ruotsalainen et al., 2011). In short, the newer version of Google Maps acts as a Local guide.

\subsection{Language translators}

There are few software applications that translate one language into others. These applications are helpful especially to travelers who visit foreign locations where they encounter unfamiliar languages. Traveling to foreign country can be tough, especially when there are language barriers. This problem can only be addressed if the travelers make use of any local guide, who can speak the local language. But the software applications can replace a local guide, by translating the unfamiliar language into the familiar languages. Few applications namely "Google Translate" would perform these tasks. These applications 
would even allow travelers to converse with the local people in their language. Google Translate provides the audio speech services, when the traveler clicks on the option, "Conversation mode". This option allows the travelers to speak in their language, captures their voice message, translates this voice message into the target language (local language) \& dictates the translation in the target language, thereby conveying the travelers' message to the local people (Azis et al., 2011). This feature is especially useful for illiterate travelers, who cannot type their messages in Google Translate. The best part of this application is its ability to work in an offline mode. It can download languages into the application \& work in an offline mode. Another feature, that is extremely useful is, "Camera Integration" option. Travelers prefer to understand the menus in the hotel, however, most of the time, they end up struggling with the menus, especially when they are at the places where they don't have any foundation in the local language.

Travelers are often out of luck when it comes to reading the signboards \& menus in the hotel, in a foreign location with an unfamiliar language. "Camera Integration" option can be used to translate the signboards \& menus in the hotels of foreign locations. The application scans the signboards \& menus, by the phone camera \& translates the information present on the signboards \& menus into the preferred language (Ma et al., 2000; Tatwany and Ouertani, 2017). This can help out the travelers who desire to read the menus in the hotel \& understand the signboards. This application also can translate the words or messages present in the images captured by the camera (Tatwany and Ouertani, 2017). This particular feature can be helpful for the travelers who wish to capture some information for the current moment \& want to have it translated later. This application helps out travelers to interact with the local people. Travelers can move to the local canteens, shopping malls \& all other recreational zones where they can interact with local people in their language, which provides a novel experience to the travelers of visiting an unfamiliar place (Chavre and Ghotkar, 2016). In the marketers' perspective, this technology improves the customer experience (traveler experience) \& customer engagement (travelers' engagement) (Bayern, 2018).

\subsection{Optimization services}

By the usage of Artificial Intelligence in combination with the Maximum Likelihood algorithm, the service providers can provide the optimization of the services. The Maximum Likelihood Algorithm makes use of the past data \& suggests the likelihood values of the prices (Moraga-González and Wildenbeest, 2008). This algorithm would suggest the timings at which the prices rise \& the timings at which the prices drop (Kumar et al., 2018; Song and Jiang, 2019). Therefore, it suggests the best timings to the customers in terms of price. This technology is used in many areas of tourism, such as booking a hotel/flight/Cab services. Using this technology the customers can decide whether to book a hotel/flight/Cab or wait till the price drops (Ropero, 2011). Likewise, the Artificial Intelligence also helps in Crossselling. Cross-selling is a sales strategy, where there is a sale of complementary products to the customers. For example, if a tourist is searching for a cab-service, the Artificial Intelligence would deliver a pool of suggestions, where there are suggestions about the cab services along with the hotel services, recreational zones nearby, etc. Few online companies such as "Hopper.com" optimize the travel experience by delivering information not only on the main service but also on the additional services that complement the main service (Bulanov, 2019).

\section{Artificial intelligence affecting travel, tourism \& hospitality related factors}

Adoption of Artificial Intelligence technologies in delivering Tourism-related services: 


\subsection{Facial recognition regulating travel facilities}

Facial Recognition technologies provide hassle-free check-ins at airports \& all other stations, without any document verifications by the immigration department, customs department, etc. This facial recognition software, not only provides the hassle-free checkins but also ensures data safety \& security to the tourists by the usage of blockchain technologies (Chang and Yang, 2008; Patel, 2018). These technologies facilitate the travel process to the customers (Saulat, 2018).

\subsection{Virtual reality regulating travel, tourism \& hospitality related factors}

There is a major gap existing between the customers' expectations of the service \& actual service delivered by the service providers. The customers at a far distance are typically unaware of the tourist spots, the tourism experience of that destination. The customers would like to experience the travel \& exploration of the tourist spots before they move to the tourist spots. This is done by searching relevant information on the Internet in the form of customer reviews etc. (Kim and Hardin, 2010). They consider numerous factors about travel $\&$ tourism before they select the destination spot. The factors include Natural Resources like Scenic beauty, lakes, mountains, deserts, variety \& uniqueness of flora \& fauna, weather conditions (temperature of the region, rainfall, humidity, etc.). General Infrastructure facilities like Road, Public \& private transport. Tourist Infrastructure includes Hotel \& accommodation facilities, restaurants, bars, discotheques, clubs, theme parks, entertainment \& sports activities, water parks, zoos, casinos, trekking, adventure activities, shopping malls, etc. Destination tourism infrastructure includes Human resources, safety measures at that place (Beerli and Martin, 2004; Kaushik et al., 2010; Seyidov and Adomaitienè, 2016).

With the advent of Virtual reality technologies, the customers can get first-hand information on most of these factors unlike reading the customer reviews. Virtual Reality (VR) technology creates a simulated environment that gives an experience of virtual reality. The customer experiences the environment to a great extent in 3D, digital world. This technology addresses the major limitation that exists between the customer \& service provider (Guttentag, 2010; Yung and Khoo-Lattimore, 2019). Looking at the virtual reality videos, the customers can experience the scenic beauty of the Natural resources like Scenic beauty, lakes, mountains, deserts, variety \& uniqueness of flora \& fauna, weather conditions, General Infrastructure facilities like Road, Public \& private transport, Tourist infrastructure like Hotel \& accommodation facilities, restaurants, bars, discotheques, clubs, theme parks, entertainment \& sports activities, water parks, zoos, casinos, trekking, adventure activities, shopping malls, Destination tourism infrastructure like Human resources, safety measures at that place etc. (Jung et al., 2016; Jung et al., 2017). The customers can have comprehensive first-hand information, which allows them to determine the selection of the tourist destination spot. In the recent past, many companies have started to use Virtual reality technology in promoting destinations \& hotel experiences. These technologies not only provide the information on all these factors, rather provide the first-hand customer experience, which motivates them to travel \& experience the service (Van Kerrebroeck et al., 2017).

Thus, Virtual reality technologies help the tourists in accessing the Natural resources, General Infrastructure facilities, Tourist infrastructure facilities, Destination tourism infrastructure, which further influence their purchase behavior \& decision-making process.

\subsection{Chatbots regulating destination tourism infrastructure \& tourist infrastructure facilities}

Chatbots are typically computer software machines, which are pre-programmed to answer

the simple questions raised by the customers (Oh et al., 2017). Customers after stepping 
into the hotel rooms are loaded with numerous questions ranging from the destination tourism infrastructure to tourist infrastructure. Customers ask numerous questions to the chatbots like facilities in the hotel, lunch \& dinner timings, items served during lunch, dinner, gym facilities, services available in the hotel, safety measures, etc. (Gajdošík and Marciš, 2019). Hence, Chatbots provide all the information related to Destination Infrastructure. In addition to that, chatbots also provide the information related to Tourist Infrastructure which includes nearby bars, discotheques, clubs, theme parks, entertainment \& sports activities, water parks, zoos, casinos, trekking, adventure activities, shopping malls, etc. (Boiano et al., 2019; Gajdošík and Marciš, 2019). Thus, Chatbots provide all the information related to the Destination tourism infrastructure \& Tourist Infrastructure.

\subsection{Robots regulating hospitality related facilities}

Recent surveys report that "Smart hospitality" is expected to grow over 25 per cent by 2021. Robots surprise the customers by providing unexpected services, keeping the customers continuously engaged, thereby, creating a novel \& pleasant experience in the minds of the customers. Robots in the hotel assist the customers by directing them to their hotel rooms, carrying the luggage to their room, maintaining house-keeping services, serving the food \& snacks (Ivanov and Webster, 2019). Thus, Robots continuously enhance Customer engagement \& Customer experience by providing novel services providing assistance in the hospitality facilities (Sharma, 2016).

\subsection{Google maps regulating general infrastructure \& tourist infrastructure facilities}

Al technology present in Google Maps uses GPS to provide information on the General Infrastructure facilities like Road, Public \& private transport. Al technology used in vehicles these days uses GPS to provide information about road accidents, traffic jams \& plans the shortest or alternate route that can escape the traffic jam. The newer version VPS would even provide the details about the nearby shops, companies, hotels, malls, cinema theatres, restaurants, canteens, recreational zones, etc., thereby providing the Locationbased experiences (Anup et al., 2017; Xiao et al., 2018). Thus, the Al technology used in the Google Maps provides the information on the Tourist Infrastructure which includes nearby Hotel \& accommodation facilities, restaurants, bars, discotheques etc. (Hallo et al., 2012; Walder, 2013). Thus, Google Maps helps tourists in accessing General Infrastructure \& Tourist Infrastructure facilities.

\subsection{Language translators regulating destination tourism infrastructure}

Language Translators would help out the Tourists to communicate with the local residents in their local language (Azis et al., 2011). These language translators would replace a local guide, by translating the unfamiliar language into the familiar languages to the tourists \& conveying the tourist messages to the local residents. Thereby, it acts as a key element in Destination tourism infrastructure replacing human resources (local guides) (Ma et al., 2000; Tatwany and Ouertani, 2017). Thus, Language Translators provide few facilities to the tourists that are included under the Destination tourism infrastructure.

\subsection{Optimization services regulating tourist infrastructure}

Optimization services that include cross-selling the products, optimizing the prices using the Maximum Likelihood algorithm, addresses the General Infrastructure facilities like Road, Public \& private transport, by providing the optimum prices of the flights, cab services, etc. (Ropero, 2011). This optimization services provide numerous information on the optimum prices of the tourist infrastructure. It includes Hotel \& accommodation facilities, restaurants, bars, discotheques, clubs, theme parks, entertainment \& sports activities, water parks, 
zoos, casinos, trekking, adventure activities, shopping malls, etc. (Kumar et al., 2018; Song and Jiang, 2019). It provides the best available options to the customers by listing optimum prices. Thus, the Optimization Services provide few facilities that are included under tourist infrastructure.

\section{Challenges for artificial intelligence in the tourism}

Although the Artificial Intelligence is excelling rapidly, there is still a limitation of its usage by the illiterates (Reddy, 2006). These limitations have to be and will be surpassed as on when demanded with the innovative solutions coupled with the emerging technologies and updating policies. No matter what all areas Al replaces human efforts giving rise to the debate of Al replacing Human Intelligence, it is still to answer and resolve many unanswered questions in various segments of business. Despite the fact that "Artificial Intelligence" is providing monetary benefits by replacing employees \& non-monetary benefits by providing a unique experience to the customers, it still cannot surpass human intelligence, as it is still an emerging area (Laurent et al., 2015).

Another major challenge in the use of $\mathrm{Al}$ is the safety \& security of data. This major concern in the application of $\mathrm{Al}$ in some of the crucial sectors like finance and military is a continuous challenge. For example, using the Blockchain technologies in Facial Recognition software ensures data safety \& security; some countries are still reluctant to use the Facial recognition technology due to the privacy \& data-security issues (Bowyer, 2004). Chatbots, hotels store the past purchase history, travel history which challenges the data privacy \& security issues. It is a challenge to privacy \& data security (Kannan and Bernoff, 2019).

A major problem with these software-controlled services is that a small malware attack can disrupt the software programs \& the operations conducted by the service providers, which further leads to chaos. Though the Al technology is advanced \& forward-looking, the small service providers cannot afford for these technologies, as it requires a huge investment (Murphy et al., 2017).

Although Chatbots \& Robots are able to replace the human workforce, the customers still rely on the human workforce, when it comes to queries that involve complexity. The machines like chatbots are only limited to answer simple questions. These technologies use the keywords in the questions to provide the answers. When there is an emergency \& complex issue to be sorted out, the customers still rely on the human workforce (Lommatzsch, 2018).

\section{Future applications of $A I$ in travel \& tourism}

There are a lot of avenues and areas in the Travel \& Tourism industry where there is a greater scope to apply Al for improved services. These may include unexpected and surprising ones. Artificial Intelligence technology can transform the entire hotel room into a desirable tourist spot. After entering the hotel room, the customers can select the option to transform their entire room into their favorite destination spot. By selecting such an option, the entire room is transformed into a virtual 3D world that resembles their favorite destination spot. The customer can experience the $3 \mathrm{D}$ view of their favorite destination spot inside the room (Wei, 2019).

Although there is a rejection of Facial Recognition technologies due to the issues of data privacy \& Security, future Al technologies may solve such issues by incorporating more robust blockchain technologies that assure data privacy \& security (Leong, 2019). In the future, we may see the Robots serving the hotel guests in directing them to their room, carrying their luggage, serving them food \& snacks, housekeeping services, etc. This technology is currently used in a few hotels (Yang et al., 2020). 
In the future, the Visual Positioning System (VPS) may take over the Global Positioning System (GPS). VPS is an advanced technology that provides the live view of the real world \& visual landmarks in front of the travelers in the form of shops, companies, hotels, malls, cinema theatres, restaurants, canteens, recreational zones, etc., thereby providing the Location-based experiences. There might be many more untouched and unexpected points related to service and customer touchpoints, where Al may be applied in the future.

\section{Conclusion}

With every passing day, the presence of Artificial intelligence in the tourism scene is increasing. Due to the widening application of innovative technology, it is expected that the tourism industry will reach unimaginable heights in the future. As per a recent research study, the global travel technology market, which encompasses Artificial Intelligence, is expected to grow by more than 9 per cent during the period 2010 and 2023. One of the main factors for the expected growth is the prosperous performance of the travel and tourism industry. But the application of innovative and novel technologies such as Artificial Intelligence, and Machine Learning will bring about significant changes at the industrial level. The technological factors can mold the industry landscape and the processes that are conducted by tourism businesses. According to an article by Forbes, due to the rise in the overall application of $\mathrm{Al}$ in the travel and tourism industry, many new jobs will be created. It is believed that between 2018 and 2022, the aviation industry and the tourism industry will see a high level of retraining so that human factors can adapt to the evolving technological infrastructure. It is expected that almost 58 million new jobs will be created by the year 2022. Such a scheduled change could help to deal with the existing unemployment problem.

In the technology-driven times, the rise in the Al footprint in the tourism industry is a good sign. This is because it indicates that the industry can make the optimum use of the latest technology to improve efficiency and productivity. The customers of the tourism industry will benefit due to the improved level of satisfaction. At the same time, the tourism business undertakings will be able to have better control over the processes. The business processes will be automated to a great extent, and the business operations and protocols will be streamlined in nature.

Even though the application of Artificial Intelligence technology will give rise to many benefits at the industry level, the organizational level as well as the customer level, it can also give rise to numerous challenges and complexities. For instance, introducing different types of $\mathrm{Al}$ in the business context of the tourism industry would not be an easy job. Business undertakings would need adequate financial resources to build a secure and robust technical infrastructure. The increase in the use of robots, chatbots, and other Al technologies would mean that the actual human interaction would be restricted in the tourism industry. This could have an adverse implication on the traveling and tourism experience of the end-users. The technology-driven approach could give rise to new, complex, and challenging technical issues that are not yet known. The marketers operating in the tourism industry would have to integrate technology seamlessly so that the technology would be easy to use, and at the same time, it would be beneficial for all the stakeholders. Such a process could be quite lengthy as the Artificial Intelligence technology is still in an early stage.

The Artificial Intelligence concept is quite new and very powerful. There is a need to carry out more research studies on the Al concept as well as its application in the industrial tourism setting. Additional studies will shed light on the complexities that might arise before business undertakings in the tourism industry due to the application of Al technology (Dirican, 2015). Many technical experts have been skeptical of Al such as Stephen Hawking. So it is necessary to carry out a holistic assessment if the new and unique form of technology as its implications would be severe. The concept of robotics and Artificial 
Intelligence could have a direct impact on the human factors that are currently functioning in the industry. Thus there is a need to conduct comprehensive research studies on $\mathrm{Al}$ in tourism so that the overall implication of the technology can be critically assessed. It will help to capture the positive as well as the negative impact on the technology on the industry, the businesses, and the customers.

\section{References}

Anup, S., Goel, A. and Padmanabhan, S. (2017), "Visual positioning system for automated indoor/outdoor navigation", TENCON 2017-2017 IEEE Region 10 Conference, pp. 1027-1031.

Anurag (2018), "4 Emerging trends of artificial intelligence in travel", available at: www.newgenapps. com/blog/artificial-intelligence-in-travel-emerging-trends (accessed 5 September 2019).

Azis, N.A., Hikmah, R.M., Tjahja, T.V. and Nugroho, A.S. (2011), "Evaluation of text-to-speech synthesizer for indonesian language using semantically unpredictable sentences test: indoTTS, eSpeak, and google translate TTS", 2011 International Conference on Advanced Computer Science and Information Systems, pp. 237-242.

Barnes, S. (2016), "Understanding virtual reality in marketing: nature, implications and potential: implications and potential", available at: https://ssrn.com/abstract=2909100 (accessed 3 November 2016).

Bayern, M. (2018), "5 Ways Al powers business travel", available at: www.techrepublic.com/article/5ways-ai-powers-business-travel/ (accessed 5 September 2019).

Beerli, A. and Martin, J.D. (2004), "Factors influencing destination image", Annals of Tourism Research, Vol. 31 No. 3, pp. 657-681.

Boiano, S., Borda, A. and Gaia, G. (2019), "Participatory innovation and prototyping in the cultural sector: a case study", Proceedings of EVA, London, pp. 18-26.

Bowyer, K.W. (2004), "Face recognition technology: security versus privacy", IEEE Technology and Society Magazine, Vol. 23 No. 1, pp. 9-19.

Bulanov, A. (2019), "Benefits of the use of machine learning and Al in the travel industry", available at: https://djangostars.com/blog/benefits-of-the-use-of-machine-learning-and-ai-in-the-travel-industry/ (accessed 2 September 2019).

Chang, H.-L. and Yang, C.H. (2008), "Do airline self-service check-in kiosks meet the needs of passengers?", Tourism Management, Vol. 29 No. 5, pp. 980-993.

Chavre, P. and Ghotkar, A. (2016), "Scene text extraction using stroke width transform for tourist translator on android platform", 2016 International Conference on Automatic Control and Dynamic Optimization Techniques (ICACDOT), IEEE.

Chawla, S. (2019), "7 Successful applications of Al \& machine learning in the travel industry", available at: https://hackernoon.com/successful-implications-of-ai-machine-learning-in-travel-industry-3040f3e1d48c (accessed 5 September 2019).

Dirican, C. (2015), "The impacts of robotics, artificial intelligence on business and economics", ProcediaSocial and Behavioral Sciences, Vol. 195, pp. 564-573.

Gajdošík, T. and Marciš, M. (2019), "Artificial intelligence tools for smart tourism development”, Computer Science On-line Conference, Springer.

Guttentag, D.A. (2010), "Virtual reality: applications and implications for tourism", Tourism Management, Vol. 31 No. 5, pp. 637-651.

Hallo, J.C., Beeco, J.A., Goetcheus, C., McGee, J., McGehee, N.G. and Norman, W.C. (2012), "GPS as a method for assessing spatial and temporal use distributions of nature-based tourists", Journal of Travel Research, Vol. 51 No. 5, pp. 591-606.

Issa, H., Sun, T. and Vasarhelyi, M.A. (2016), "Research ideas for artificial intelligence in auditing: the formalization of audit and workforce supplementation", Journal of Emerging Technologies in Accounting, Vol. 13 No. 2, pp. 1-20.

Ivanov, S. and Webster, C. (2019), "Perceived appropriateness and intention to use service robots in tourism", Information and Communication Technologies in Tourism 2019, Springer, Cham, pp. 237-248. 
Ivanov, S. and Webster, C. (2017), "Adoption of robots, artificial intelligence and service automation by travel, tourism and hospitality companies - a cost-benefit analysis", International Scientific Conference Contemporary tourism - traditions and innovations, 19-21 October, Sofia University.

Ivanov, S.H., Webster, C. and Berezina, K. (2017), "Adoption of robots and service automation by tourism and hospitality companies", Revista Turismo \& Desenvolvimento, Vol. 27 No. 28, pp. 1501-1517.

Jung, T., Tom Dieck, M.C., Lee, H. and Chung, N. (2016), "Effects of virtual reality and augmented reality on visitor experiences in museum", in Inversini A. and Schegg R. (Eds), Information and Communication Technologies in Tourism 2016, Springer, Cham.

Jung, T., Tom Dieck, M.C., Moorhouse, N. and Tom Dieck, D. (2017), "Tourists' experience of virtual reality applications", 2017 IEEE International Conference on Consumer Electronics (ICCE), IEEE.

Kannan, P. and Bernoff, J. (2019), "The future of customer service is Al-Human collaboration", MIT Sloan Management Review.

Kaushik, N., Kaushik, J., Sharma, P. and Rani, S. (2010), "Factors influencing choice of tourist destinations: a study of North India", IUP Journal of Brand Management, Vol 7 Nos 1/2, pp. 116-132.

Kim, J. and Hardin, A. (2010), "The impact of virtual worlds on word-of-mouth: improving social networking and servicescape in the hospitality industry", Journal of Hospitality Marketing \& Management, Vol. 19 No. 7, pp. 735-753.

Kim, T., Kim, M.C., Moon, G. and Chang, K. (2014), "Technology-based self-service and its impact on customer productivity", Services Marketing Quarterly, Vol. 35 No. 3, pp. 255-269.

Kumar, R., Li, A. and Wang, W. (2018), "Learning and optimizing through dynamic pricing", Journal of Revenue and Pricing Management, Vol. 17 No. 2, pp. 63-77.

Kumar, V.M., Keerthana, A., Madhumitha, M., Valliammai, S. and Vinithasri, V. (2016), "Sanative chatbot for health seekers", International Journal of Engineering and Computer Science, Vol. 5 No. 3, pp. $16022-16025$.

Laurent, P. Chollet, T. and Herzberg, E. (2015), "Intelligent automation entering the business world", available at: www2.deloitte.com/content/dam/Deloitte/lu/Documents/operations/lu-intelligent-automation business-world.pdf (accessed 5 March 2018).

Leong, B. (2019), "Facial recognition and the future of privacy: I always feel like... somebody's watching me", Bulletin of the Atomic Scientists, Vol. 75 No. 3, pp. 109-115.

Lommatzsch, A. (2018), "A next generation Chatbot-Framework for the public administration", International Conference on Innovations for Community Services, Springer.

McCormick, J. Doty, C.A. Sridharan, S. Curran, R. Evelson, B. Hopkins, B. Little, C. Leganza, G. Purcell, B. and Miller, E. (2016), "Predictions 2017: artificial intelligence will drive the insights revolution", FORRESTER research for customer insights professionals", available at: www.forrester.com/report/ Predictions+2017+Artificial+Intelligence+Will+Drive+The+Insights+Revolution/-/E-RES133325 (accessed 12 May 2019).

Ma, D. Lin, Q. and Zhang, T. (2000), "Mobile camera based text detection and translation", available at: https://stacks.stanford.edu/file/druid:my512gb2187/Ma_Lin_Zhang_Mobile_text_recognition_and_ translation.pdf (accessed 5 Spetember 2019).

Makar, M.G. and Tindall, T.A. (2014), "Automatic message selection with a chatbot", Google Patents.

Marouane, C., Maier, M., Feld, S. and Werner, M. (2014), "Visual positioning systems - an extension to MoVIPS", 2014 International Conference on Indoor Positioning and Indoor Navigation (IPIN), IEEE, pp. 95-104.

Moraga-González, J.L. and Wildenbeest, M.R. (2008), "Maximum likelihood estimation of search costs", European Economic Review, Vol. 52 No. 5, pp. 820-848.

Murphy, J., Hofacker, C. and Gretzel, U. (2017), "Dawning of the age of robots in hospitality and tourism: challenges for teaching and research", European Journal of Tourism Research, Vol. 15, pp. 104-111.

Nagaraj, S. (2019), "Al enabled marketing: what is it all about?", International Journal of Research in Commerce, Economics and Management, Vol. 8 No. 6, pp. 501-518.

Nagaraj, S. (2020), "Marketing analytics for customer engagement: a viewpoint", International Journal of Information Systems and Social Change (IJISSC), Vol. 11 No. 2, pp. 41-55. 
Nagaraj, S. and Singh, S. (2018), "Investigating the role of customer brand engagement and relationship quality on brand loyalty: an empirical analysis", International Journal of E-Business Research (IJEBR), Vol. 14 No. 3, pp. 34-53.

Nagaraj, S. and Singh, S. (2019), "Millennial's engagement with fashion brands: a moderated-mediation model of brand engagement with self-concept, involvement and knowledge", Journal of Fashion Marketing and Management: An International Journal, Vol. 23 No. 1, pp. 2-16, doi: 10.1108/JFMM-042018-0045.

Oh, K.J., Lee, D., Ko, B. and Choi, H.J. (2017), "A chatbot for psychiatric counseling in mental healthcare service based on emotional dialogue analysis and sentence generation", 2017 18th IEEE International Conference on Mobile Data Management (MDM), IEEE.

Patel, V. (2018), "Airport passenger processing technology: a biometric airport journey", available at: https://commons.erau.edu/edt/385/ (accessed 5 September 2019).

Peranzo, P. (2019), "Al assistant: the future of travel industry with the increase of artificial intelligence", available at: www.imaginovation.net/blog/the-future-of-travel-with-the-increase-of-ai/ (accessed 5 September 2019).

Reddy, R. (2006), "Robotics and intelligent systems in support of society", IEEE Intelligent Systems, Vol. 21 No. 3, pp. 24-31.

revfine.com (2019), "How artificial intelligence (AI) is changing the travel industry", available at: www. revfine.com/artificial-intelligence-travel-industry (accessed 20 June 2019).

Ropero, M.A. (2011), "Dynamic pricing policies of hotel establishments in an online travel agency", Tourism Economics, Vol. 17 No. 5, pp. 1087-1102.

Ruotsalainen, L., Kuusniemi, H. and Chen, R. (2011), "Visual-aided two-dimensional pedestrian indoor navigation with a smartphone", Journal of Global Positioning Systems, Vol. 10 No. 1, pp. 11-18.

Russell, S. and Norvig, P. (2016), Artificial Intelligence: A Modern Approach, Pearson, New York, NY.

Saulat, A. (2018), "Four ways Al is re-imagining the future of travel", available at: www.mindtree.com/ blog/four-ways-ai-re-imagining-future-travel (accessed 5 September 2019).

Seal, P.P. (2019), "Guest retention through automation: an analysis of emerging trends in hotels in Indian Sub-Continent", in Batabyal. and D, (Ed.), Global Trends, Practices, and Challenges in Contemporary Tourism and Hospitality Management, IGI Global, pp. 58-69.

Seyidov, J. and Adomaitienè, R. (2016), "Factors influencing local tourists' decision-making on choosing a destination: a case of Azerbaijan", Ekonomika, Vol. 95 No. 3, pp. 112-127.

Sharma, D. (2016), "Enhancing customer experience using technological innovations: a study of the Indian hotel industry", Worldwide Hospitality and Tourism Themes, Vol. 8 No. 4, pp. 469-480.

sites.tcs.com (2019), "Getting smarter by the sector: how 13 global industries use artificial intelligence", available at: http://sites.tcs.com/artificial-intelligence/wp-content/uploads/TCS-GTS-how-13-globalindustries-use-artificial-intelligence.pdf (accessed 5 June 2019).

Song, H. and Jiang, Y. (2019), "Dynamic pricing decisions by potential tourists under uncertainty: the effects of tourism advertising", Tourism Economics, Vol. 25 No. 2, pp. 213-234.

Tatwany, L. and Ouertani, H.C. (2017), "A review on using augmented reality in text translation”, 20176 th International Conference on Information and Communication Technology and Accessibility (ICTA), IEEE.

thinkwithgoogle.com (2016), "How mobile influences travel decision making in Can't-Wait-to-Explore moments", available at: www.thinkwithgoogle.com/consumer-insights/mobile-influence-travel-decisionmaking-explore-moments/ (accessed 5 September 2019).

Van Kerrebroeck, H., Brengman, M. and Willems, K. (2017), "Escaping the crowd: an experimental study on the impact of a virtual reality experience in a shopping mall", Computers in Human Behavior, Vol. 77, pp. 437-450.

Viglia, G., Furlan, R. and Ladron-de-Guevara, A. (2014), "Please, talk about it! when hotel popularity boosts preferences", International Journal of Hospitality Management, Vol. 42, pp. 155-164.

Walder, R. (2013), "Method and device for presenting information associated to geographical data", Google Patents.

Wei, W. (2019), "Research progress on virtual reality (VR) and augmented reality (AR) in tourism and hospitality: a critical review of publications from 2000 to 2018", Journal of Hospitality and Tourism Technology, Vol. 10 No. 4. 
Wilde, J.S. (2017), "Systems and methods for improved data integration in virtual reality architectures", Google Patents.

Xiao, A., Chen, R., Li, D., Chen, Y. and Wu, D. (2018), "An indoor positioning system based on static objects in large indoor scenes by using smartphone cameras", Sensors, Vol. 18 No. 7, p. 2229.

Yang, L., Henthorne, T.L. and George, B. (2020), "Artificial intelligence and robotics technology in the hospitality industry: Current applications and future trends", Digital Transformation in Business and Society, Springer, pp. 211-228.

Yung, R. and Khoo-Lattimore, C. (2019), "New realities: a systematic literature review on virtual reality and augmented reality in tourism research", Current Issues in Tourism, Vol. 22 No. 17, pp. 2056-2081.

\section{Corresponding author}

Nagaraj Samala can be contacted at: raajsamala.phd@gmail.com

For instructions on how to order reprints of this article, please visit our website: www.emeraldgrouppublishing.com/licensing/reprints.htm

Or contact us for further details: permissions@emeraldinsight.com 